\title{
Penentuan Setelan Rotor Mesin Open End Untuk Pembuatan Benang Ne 6 sebagai Upaya Jaminan Atas spesifikasi dan Kualitas Pada Workshop Pemintalan di Ak-Tekstil Solo
}

\author{
Hendri Pujianto ${ }^{1 *}$, Fajar Pitarsi Dharma ${ }^{1}$, Darmawan Hindardi ${ }^{1}$,Tuti Purwati \\ Tuwarno $^{1}$
}

\begin{abstract}
${ }^{1}$ Laboratorium Pemintalan dan Pertenunan, Akademi Komunitas Industri Tekstil dan Produk Tekstil Surakarta, Surakarta, 57126, e-mail: hendrip@ak-tekstilsolo.ac.id "Coresponding author
\end{abstract}

Submisi: 24 Juni 2021; Penerimaan: 2 Agustus 2021

\begin{abstract}
ABSTRAK
Mesin open end adalah salah satu jenis mesin yang digunakan dalam proses pemintalan benang. Fungsi utama mesin open end adalah memproses sliver dari mesin drawing dan memisahkan sliver menjadi serat tungga. Serat dikirim ke rotor melalui saluran vakum, rotor berputar pada kecepatan yang sangat tinggi dan memadatkan sebagian serat menjadi bentuk khusus dengan memutar serat pada saat yang bersamaan. Rotor adalah jantung dari proses pemintalan yang mempengaruhi kualitas benang, kinerja pemintalan, produktivitas dan keekonomisan proses. Pembuatan benang Ne pada industri pemintalan diproses pada mesin open end dan untuk benang Ne 6 menggunakan rotor tipe C341 dan C533 agar dapat memenuhi spesifikasi dan kualitas benang Ne 6. Penggunaan rotor yang berbeda tipe menghasilkan spesifikasi dan kualitas benang Ne 6 yang berbeda pula. Solusi dari permasalahan ini adalah menentukan setelan rotor mesin open end yang paling tepat untuk memenuhi spesifikasi dan kualitas benang Ne 6. Percobaan produksi dilakukan di spindel nomor 7 dan 9 pada mesin. Setelah dilakukan pengamatan terhadap percobaan produksi dengan dua tipe rotor yang berbeda maka didapatkan rotor tipe C341 yang lebih memenuhi spesifikasi dan kualitas untuk pembuatan benang $\mathrm{Ne} 6$. Pada spindel 7 mendapat rata-rata Ne 5,86 dan nilai Cvm\% yaitu 12,56, spindel 9 mendapat rata-rata Ne 5,94 dan nilai Cvm\% yaitu 14,22. Nilai Ne telah memenuhi standar spesifikasi benang $\mathrm{Ne} 6$ yaitu 5,8-6,2 $\mathrm{Ne}$ dan nilai Cvm\% telah memenuhi toleransi jaminan kualitas ketidakrataan benang Cvm\%=1,11-1,25 nilai Um\%.
\end{abstract}

Kata kunci: Mesin Opend End; Rotor; Benang Ne; Spesifikasi; Kualitas

\section{PENDAHULUAN}

Pemintalan adalah proses yang digunakan untuk menghasilkan serat atau filamen dari polimer alam atau sintetis, atau mengubah serat dan filamen alami atau buatan menjadi benang dengan cara memutar atau cara lain untuk mengikat bersama-sama serat atau filamen yang menghasilkan panjang benang yang relatif halus dan kontinu [4]. Salah satu benang yang dihasilkan adalah benang open end melalui mesin open end.
Fungsi utama mesin open end adalah memproses sliver dari mesin drawing, memisahkan sliver menjadi serat tunggal, kemudian serat dikirim ke rotor melalui saluran vakum, rotor berputar pada kecepatan yang sangat tinggi dan memadatkan sebagian serat menjadi bentuk khusus dengan memutar serat pada saat yang bersamaan [2].

Saat ini ada dua teknik menggunakan metode open end secara komersial, yaitu pemintalan rotor dan 
pemintalan gesekan. Konsolidasi pada pemintalan rotor dicapai dengan puntiran mekanis. Torsi yang menghasilkan puntiran pada benang diterapkan oleh putaran rotor. Jumlah putaran (putaran per meter) ditentukan oleh rasio antara kecepatan rotor (rpm) dan kecepatan take-up (meter/menit). Setiap pergantian rotor menghasilkan giliran putaran. Operasi penggulungan pada pemintalan rotor benar-benar terpisah dari operasi peregangan dan pemuntiran [4].

Rotor adalah jantung dari proses pemintalan yang mempengaruhi kualitas benang, kinerja pemintalan, produktivitas, dan keekonomisan proses. Parameter penting dari rotor adalah sebagai berikut diameter rotor, konfigurasi alur rotor, kecepatan rotor, sudut dinding geser [5].

Rotor yang digunakan dalam industri pemintalan benang $\mathrm{Ne} 6$ adalah rotor tipe C341 dan C533. Oleh karena penggunaan rotor yang berbeda dalam pembuatan benang $\mathrm{Ne} 6$ maka didapati spesifikasi dan kualitas benang $\mathrm{Ne}$ yang berbeda pula.

Berdasarkan latar belakang tersebut maka penelitian ini dilakukan dengan tujuan untuk menentukan setelan rotor yang paling tepat memenuhi spesifikasi dan kualitas benang $\mathrm{Ne} 6$ di mesin open end sebagai upaya jaminan atas spesifikasi dan kualitas benang $\mathrm{Ne} 6$.

\section{METODOLOGI}

Penelitian dilaksanakan dengan mengambil data percobaan produksi benang pada 2 jenis rotor yaitu rotor tipe C341 dan rotor tipe C533 dengan 2 jenis spindel nomor 7 dan 9 untuk setiap jenis rotor. Setelah itu melakukan pengujian spesifikasi nomor benang (nilai $\mathrm{Ne}$ ) dan kualitas benang (uji ketidakrataan benang).

\section{Alat dan Bahan}

Penelitian ini dilaksanakan pada laboratoriun pemintalan AK-Tekstil Solo selama 15 hari. Alat yang digunakan dalam penelitian ini adalah alat percobaan produksi dan alat uji spesifikasi dan kualitas benang. Alat percobaan produksi yang digunakan adalah mesin open end Rieter R35 dengan spindel nomor 7 dan 9 dan rotor tipe C533 diameter $33 \mathrm{~mm}$ dan tipe C341 diameter $41 \mathrm{~mm}$. Alat uji yang digunakan adalah Yarn Eveness and Hairness Tester Covatest Textechno, Yarn Reeling Machine Textechno dan Electronic Balance Sartorius. Bahan yang digunakan adalah Drawn Sliver Cotton $100 \%$.

Spesifikasi alat dan bahan yang digunakan dalam penelitian ini adalah sebagai berikut:

1. Mesin open end (Rieter R35)

Mesin open end (Rieter R35) digunakan pada proses akhir pemintalan dimana mesin ini digunakan untuk proses pemintalan benang dan dapat membuat benang $\mathrm{Ne} 3-\mathrm{Ne} 40$, benang dapat diproduksi pada kecepatan pengiriman hingga $200 \mathrm{~m} /$ menit. Mesin open end (Rieter R35) dapat dilihat pada Gambar 1.

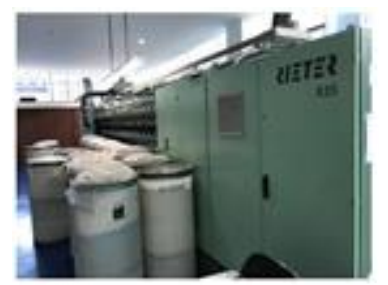

Gambar 1. Mesin open end (Rieter R35)

\section{Spindel}

Spindel adalah poros utama yang memiliki kecepatan untuk memutar rotor. Nomor spindel yang dipakai untuk penelitian ini adalah nomor 7 dan 9 dan dapat dilihat pada Gambar 2. 


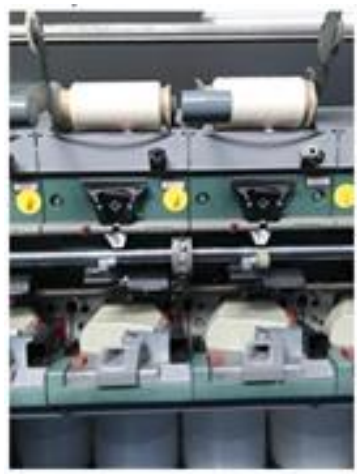

Gambar 2. Spindel yang digunakan untuk percobaan

3. Sliver

Sliver adalah serat individu yang telah melalui proses-proses pembentukan dikumpulkan dan disaukan menjadi ali yang besar dan getas. Sliver yang digunakan pada mesin open end adalah drawn sliver atau sliver yang dihasilkan oleh mesin drawing karena siklus pembuatan benang OE sebelum pemintalan dengan mesin open end melalui proses pembentukan sliver dengan mesin drawing [2]. Drawn sliver dapat dilihat pada Gambar 3.

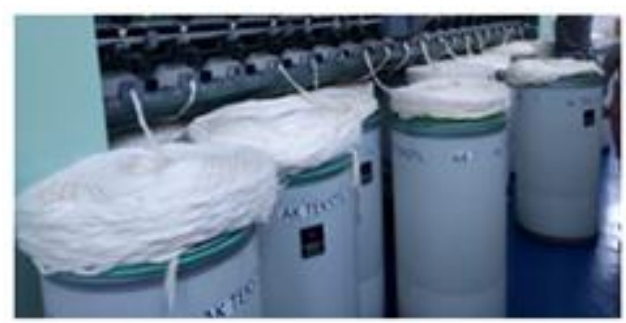

Gambar 3. Drawn sliver

\section{Rotor}

Rotor adalah tempat serat dikumpulkan di alurnya untuk membentuk pita di sekitar lingkar internalnya. Efeknya adalah terkelupasnya pita serat dari alur rotor, memungkinkan puntiran untuk mengikat serat bersama-sama ke ekor benang dan dengan demikian membentuk panjang benang baru [4]. Ilustrasi rotor saat memintal benang dapat dilihat pada Gambar 4. Rotor yang dipakai pada penelitian ini adalah rotor tipe $\mathrm{C} 533$ (diameter $33 \mathrm{~mm}$ ) C341 (diameter 41 $\mathrm{mm}$ ) dan dapat dilihat pada Gambar 5 .

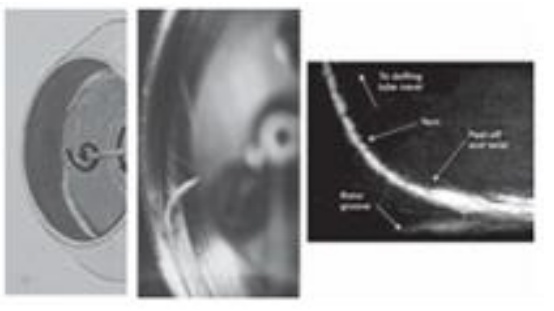

Gambar 4. Formasi Yarn ketika rotor diputer

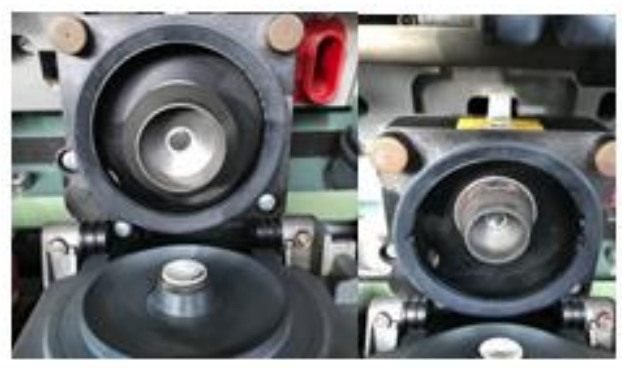

Gambar 5. Rotor tipe C533 dan C341

\section{Alat uji}

Alat uji yang digunakan dalam penelitian ini adalah Yarn eveness and Hairness Tester Covatest, Yarn Reeling Machine dan Electronic Balance. Yarn eveness and hairness tester Covatest adalah alat uji yang digunakan untuk menguji ketidakratan benang. Gambar Yarn eveness and Hairness tester Covatest dapat dilhat pada Gambar 6. Yarn Reeling Machine adalah alat uji yang digunakan untuk mengetahui nomor benang Ne. Gambar Yarn Reeling machine dapat dilhat pada Gambar 7. Electronic Balance adalah alat bantu timbang digital dengan ketelitian 1/10000 gram untuk menimbang sampel benang setelah proses penggulungan panjang sampel benang pada Yarn Reeling Machine. Gambar Electronic Balance dapat dilhat pada Gambar 8.

\section{Penentuan setting mesin open end} Penelitian dimulai dengan proses menentukan parameter setting mesin 
untuk melakukan percobaan produksi. Parameter setting mesin ditunjukan pada Tabel 1 dan Gambar 9.

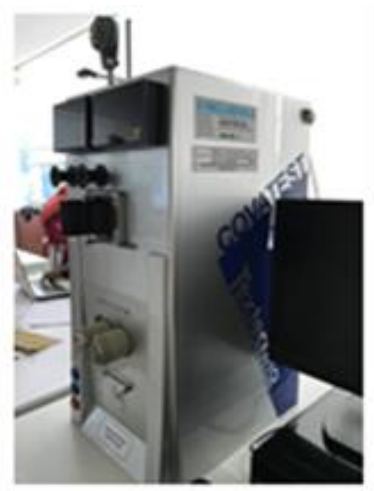

Gambar 6. Yarn eveness and hairness tester covatest

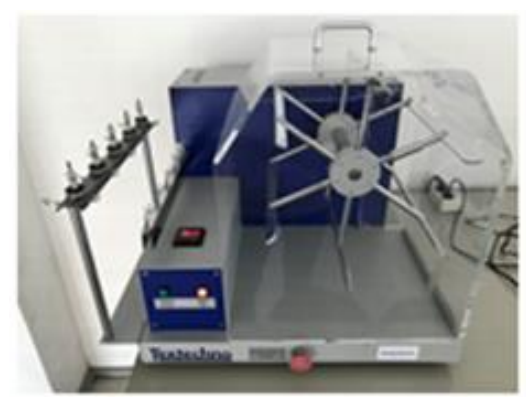

Gambar 7. Yarn reeling machine

Tabel 1. Parameter setting mesin

\begin{tabular}{cc}
\hline Item & Keterangan \\
\hline Rotor speed & 60000 \\
Opening Roll speed & 8000 \\
T/m & 348 \\
T/Inch & 8,84 \\
Ne Count & 6 \\
Ne Sliver & 0,126 \\
Diameter Opening Roll & $0.065 \mathrm{~mm}$ \\
\hline
\end{tabular}

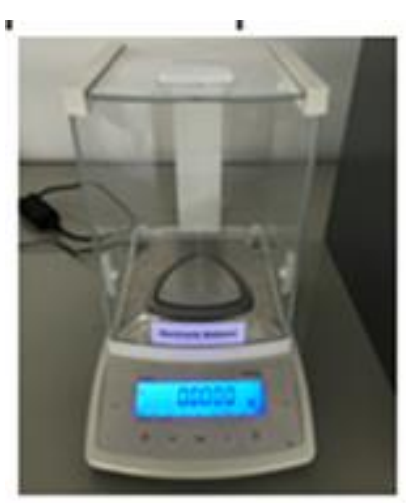

Gambar 8. Electronic balance

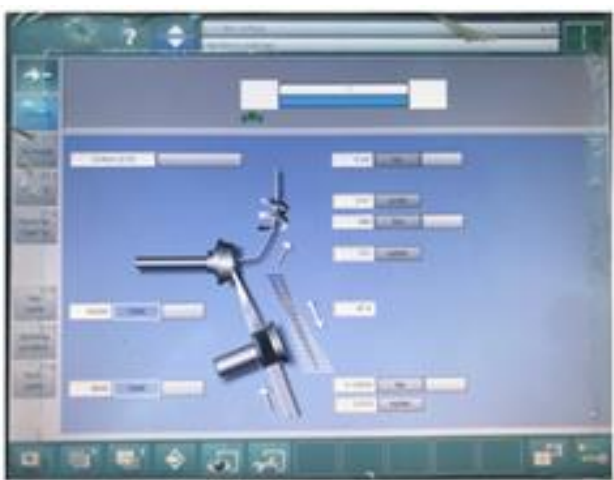

Gambar 9. Parameter setting mesin

\section{Percobaan produksi}

Pelaksanaan pengambilan data percobaan produksi dilakukan setelah persiapan alat dan bahan serta parameter mesin telah ditentukan. Pengambilan data percobaan produksi benang dilakukan pada 2 tipe rotor yaitu rotor tipe C533 dan C341 untuk 1 kali doffing dengan menggunakan spindel nomor 7 dan nomor 9. Doffing adalah setiap spindle box dengan benang, kemudian dilepas dan spindle box baru dimasukkan ke tempatnya dengan cheese roll terpasang [4]. Artinya percobaan produksi benang dilakukan 1 kali dengan 1 chesee roll yang telah diatur panjang benang untuk sekali pasang cheese roll untuk masing-masing tipe rotor dan spindel

\section{Pengujian spesifikasi nomor benang Ne dan kualitas ketidakrataan benang Pengujian spesifikasi nomor} benang Ne dilakukan sebanyak 3 kali pada masing-masing sampel percobaan produksi yang diproses pada rotor $\mathrm{C} 533$ dan C341 dengan spindel nomor 7 dan 9. Jadi total pengujian yang dilakukan sebanyak 12 kali dengan panjang benang yang dibutuhkan untuk sekali pengujian adalah 1 lea = 120 yard.

Pengujian dilakukan dengan menggunakan alat uji Yarn Reeling Machine dan Electronic Balance. Yarn Reeling Machine digunakan untuk menggulung benang, untuk 
mendapatkan panjang benang pengujian yaitu 120 yard maka penggulungan dilakukan sebanyak 80 kali karena 1 kali gulungan sebesar 1,5 yard. Setelah didapatkan panjang benang uji maka pengujian dilanjutkan dengan menimbang hasil gulugan benang pada Electronic Balance dan menghitung nomor benang Ne dengan persamaan 1 [6]:

$$
N e_{c}=\frac{\text { hanks (840yd) }}{\text { Pound (lb) }}
$$

Keterangan:

$\mathrm{Nec}=$ Nomor benang

Hanks = Standard length unit

Pound $=$ mass unit $=453,6$ gram

Pengujian kualitas benang $\mathrm{Ne} 6$ dilakukan sebanyak 3 kali pada sampel percobaan produksi yang telah diuji dan memenuhi standar spesifikasi nomor benang Ne6. Pengujian dilakukan untuk mengetahui ketidakrataan benang.

Pengujian dilakukan dengan menggunakan alat uji Yarn Eveness and Hairness Tester Covatest dengan kecepatan run test yaitu 2,5 menit x 400 $\mathrm{m} /$ menit atau panjang benang yang diuji setara dengan 1000 meter. Parameter hasil dari pengujian ketidakrataan benang yang digunakan adalah Um\% dan Cvm\%, dimana Cvm\% $=1,11$ $1,25 \mathrm{U} \%$

\section{Alur Penelitian}

Identifikasi masalah dalam menemukan solusi pada penelitian menentukan setelan rotor yang paling tepat memenuhi spesifikasi dan kualitas benang, maka studi awal dilakukan dimulai dari pemilihan alat dan bahan untuk percobaan produksi benang, alur penelitian ditunjukan pada Gambar 10.

Hasil akhir dari penelitian ini adalah sebuah setelan rotor yang paling tepat atau dengan kata lain dapat memenuhi jaminan spesifikasi dan kualitas benang $\mathrm{Ne} 6$.

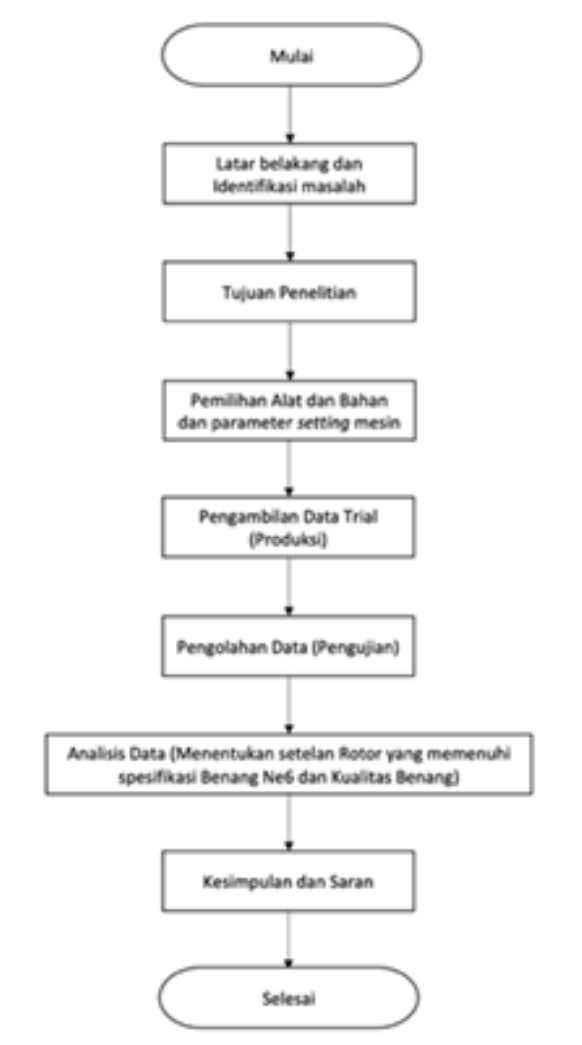

Gambar 10. Alur penelitian

\section{HASIL DAN PEMBAHASAN}

Pengambilan data percobaan produksi benang dilakukan pada 2 tipe rotor yaitu rotor tipe C533 dan C341 dengan 2 jenis spindel nomor 7 dan 9 yang akan dibandingkan hasilnya melalui sampel yang telah dibuat dengan pengujian nomor benang $\mathrm{Ne}$. $\mathrm{Ne}$ merupakan penomoran benang tidak langsung. Sistem penomoran tidak langsung atau berat tetap didasarkan pada panjang serat setiap berat tertentu yang tetap. Dengan sistem penomoran tidak langsung atau berat tetap, maka jika nomor benang makin besar maka benang akan semakin halus atau semakin kecil, sebaliknya makin kecil benangnya makin besar nomornya. Sistem penomoran ini biasanya digunakan untuk mengukur benang staple (serat pendek) dan di notasikan dalam $\mathrm{Ne} 1$ dan $\mathrm{Nm}[3]$. 
kali $\begin{array}{r}\text { Pengujian dilakukan sebanyak } 3 \\ \text { masing-masing sampel }\end{array}$ menggunakan Yarn Reeliing Machine, lalu ditimbang dengan menggunakan Electronic Balance dan dilakukan perhitungan nilai $\mathrm{Ne}$.

Diketahui:

Panjang sampel pengujian adalah 120 yard. Berat timbang sampel 1 spindel 9 rotor tipe C533 adalah 11,79 gram (1 Pound $=$ mass unit $=453,6$ gram $)$. Maka:

$N e_{c}=\frac{\text { hanks }(840 \mathrm{yd})}{\text { Pound }(\mathrm{lb})}$

$N e_{c}=\frac{\frac{120}{840} \mathrm{yard}}{\frac{11,79}{453,6} \mathrm{gram}}$

$N e_{c}=5,49$

Hasil perhitungan uji nilai Ne untuk seluruh sampel pada percobaan produksi dengan rotor tipe $\mathrm{C} 533$ dan C341 pada spindel nomor 7 dan 9 dapat dilihat pada Tabel 2.

Tabel 2. Hasil pengujian $\mathrm{Ne}$

\begin{tabular}{|c|c|c|c|}
\hline Item & Gram & $\mathrm{Ne}$ & $\begin{array}{l}\text { Putus Benang } \\
\text { Saat Produksi }\end{array}$ \\
\hline \multirow{3}{*}{$\begin{array}{c}\text { S. } 9 \\
\text { R. C533 }\end{array}$} & 11,79 & 5,49 & \multirow{3}{*}{1} \\
\hline & 11.58 & 5,59 & \\
\hline & 11,88 & 5,45 & \\
\hline Rerata & 11,75 & 5,51 & \\
\hline \multirow{3}{*}{$\begin{array}{l}\text { S.7 } \\
\text { R. } \text { C533 }\end{array}$} & 11,76 & 5,51 & \multirow{3}{*}{1} \\
\hline & 11,83 & 5,47 & \\
\hline & 11,83 & 5,47 & \\
\hline Rerata & 11,82 & 5,48 & \\
\hline \multirow{3}{*}{$\begin{array}{c}\text { S. } 9 \\
\text { R. C341 }\end{array}$} & 10,91 & 5,93 & \multirow{3}{*}{1} \\
\hline & 10.79 & 6,00 & \\
\hline & 11,09 & 5,81 & \\
\hline Rerata & 10,81 & 5,94 & \\
\hline \multirow{3}{*}{$\begin{array}{c}\text { S. } 7 \\
\text { R. C341 }\end{array}$} & 11,09 & 5,84 & \multirow{3}{*}{2} \\
\hline & 10,96 & 5,91 & \\
\hline & 11,13 & 5,82 & \\
\hline Rerata & 11,06 & 5,86 & \\
\hline \multicolumn{4}{|c|}{ Keterangan: $\mathrm{S}=$ Spindel, $\mathrm{R}=$ Rotor } \\
\hline
\end{tabular}

masuk dalam toleransi standar spesifikasi berat benang $\mathrm{Ne} 6$ yaitu 5,8$6,2 \mathrm{Ne}$. Hasil dari percobaan produksi diketahui pada spindel 7 dengan tipe rotor C341 mendapat rata-rata Ne 5,86 dan untuk rotor tipe $\mathrm{C} 533$ mendapat ratarata 5,48. Spindel 9 dengan tipe rotor C341mendapat rata-rata $\mathrm{Ne} \mathrm{5,94} \mathrm{dan}$ untuk rotor tipe $\mathrm{C} 533$ mendapat rata-rata 5,51. Jadi penggunaan rotor tipe C341 pada percobaan produksi yang memenuhi standar spesifikasi benang $\mathrm{Ne} 6$.

Setelah didapatkan hasil pengujian benang untuk standar spesifikasi benang $\mathrm{Ne}$ dan didapatkan rotor tipe C341 sebagai setelan rotor yang paling tepat memenuhi standar spesifikasi benang $\mathrm{Ne} 6$ maka selanjutnya dilakukan pengujian ketidakrataan benang untuk mengetahui kualitas benang yang dihasilkan dari sampel percobaan produksi yang dilakukan pada rotor tipe C341.

Tiga kategori kesalahan benang yang berbeda direpresentasikan berdasarkan ukuran, panjang dan frekuensi kemunculannya salah satunya adalah ketidakrataan atau ketidakteraturan. Ketidakrataan adalah parameter paling umum yang digunakan untuk mengekspresikan variasi massa pada untaian serat. Sederhananya persentase deviasi massa satuan panjang material dan disebabkan oleh distribusi serat yang tidak merata di sepanjang untai. Ketidakrataan (Um\%) sebanding dengan intensitas variasi massa di sekitar nilai rata-rata (Mass CV/Coefficient of Variation $\mathrm{Cv}_{m} \%$ ) [6].

Benang yang dipintal dari untaian serat, mengandung variasi ekstrim tertentu, yang disebut sebagai ketidaksempurnaan. Ketidaksempurna-an ini dibagi menjadi tiga kategori: tempat tipis (Thin), tempat tebal (Thick) dan serat kusut (Neps) [6]. 
Ketidaksempurnaan yang dapat diterima ditunjukkan pada Tabel 3 [5].

Tabel 3. Acceptable yarn imperfections

\begin{tabular}{cc}
\hline No. & Parameter \\
\hline 1. & Thin places $(-50 \%)$ \\
2. & Thick places $(+50 \%)$ \\
3. & Neps $(+280 \%)$ \\
\hline
\end{tabular}

Thin (benang tipis) adalah kesalahan dalam panjang yang kurang lebih sepanjang staple lenght dengan ukuran penampang $50 \%$ lebih kecil dari harga rata-rata. Thick (benang tebal) adalah kesalahan dalam panjang yang kurang lebih sepanjang staple lenght dengan ukuran penampang $50 \%$ lebih besar dari harga rata-ratanya. Neps adalah kesalahan dalam panjang 1 (satu) milimeter dengan ukuran penampang $200 \%$ dari harga rata-ratanya [1].

Untuk benang open end nilai sensitivitasnya adalah $+280 \%$ karena fakta bahwa dengan benang open end, neps cenderung dipintal ke inti benang dan oleh karena itu kurang terlihat oleh mata manusia pada produk jadi [6]. Hasil pengujian kualitas benang yang dihasilkan oleh mesin open end dengan rotor tipe C341 dengan spindel 7 dan 9 yang telah memenuhi spesifikasi benang Ne 6 ditunjukkan pada Tabel 4 .

Hubungan antara Um\% dan Cvm\% adalah jika rakitan serat yang diperlukan untuk diuji didistribusikan secara normal sehubungan dengan variasi massa, nilai Cvm adalah $1,25 \mathrm{Um} \%$. Untuk kurva sinusoidal yang sempurna, yaitu untuk rakitan serat dengan hanya variasi periodik, konversinya adalah $\mathrm{CVm} \%=1,11 \mathrm{Um} \%$. Namun, bila variasi periodik ditumpangkan oleh variasi acak kecil, konstanta konversi diantara 1,11$1,25 \mathrm{U} \%$ asalkan distribusinya simetris [6].

Tabel 4 di atas menggambarkan hasil pengujian menggunakan Yarn eveness and hairness tester Covatest untuk menguji ketidakrataan benang. Hasil pengujian ketidakrataan menunjukkan untuk hasil percobaan produksi benang Ne 6 pada rotor C341 spindel nomor 7 adalah 12,54 dan untuk spindel nomor 9 adalah 14,22. Nilai Cvm\% telah memenuhi toleransi jaminan kualitas ketidakrataan benang (Cvm\%=1,11-1,25U\%) untuk spesifikasi benang $\mathrm{Ne} 6$.

Tabel 4. Hasil uji ketidakrataan benang

\begin{tabular}{ccccccccc}
\hline Spindel & $\begin{array}{c}\text { Test N. } \\
\text { S/T }\end{array}$ & Um\% & CVm\% & $\begin{array}{c}1,11- \\
1,25 U \% \\
\text { (konversi) }\end{array}$ & $\begin{array}{c}\text { Thin/km } \\
+50 \%\end{array}$ & $\begin{array}{c}\text { Thick/km } \\
+50 \%\end{array}$ & $\begin{array}{c}\text { Neps/km } \\
+280 \%\end{array}$ & H \\
\hline \multirow{3}{*}{ No. 7} & $1 / 1$ & 10,07 & 12,54 & & 10 & 60 & 15 & 5 \\
& $1 / 2$ & 10,06 & 12,52 & & 0 & 30 & 0 & 4,89 \\
& $1 / 3$ & 10,10 & 12,58 & & 0 & 65 & 10 & 4,87 \\
\hline \multirow{2}{*}{ No. 9} & AVE & 10,08 & 12,56 & $11,19-12,6$ & 3.33 & 52 & 8.33 & 4,92 \\
\hline & $1 / 1$ & 11,59 & 14,33 & & 5 & 56 & 16 & 4,49 \\
& $1 / 2$ & 11,38 & 14,10 & & 0 & 56 & 13 & 4,43 \\
\hline & $1 / 3$ & 11,52 & 14,24 & & 10 & 48 & 14 & 4,42 \\
\hline
\end{tabular}

\section{KESIMPULAN}

Berdasarkan hasil dan pembahasan dapat disimpulkan bahwa setelan rotor yang tepat untuk jaminan spesifikasi pembuatan benang $\mathrm{Ne} 6$ (5,8-
6,2 Ne) adalah rotor tipe C 341 dengan hasil dari pengujian diketahui pada spindel 7 mendapat rata-rata $\mathrm{Ne} 5,86$ dan spindel 9 mendapat rata-rata $\mathrm{Ne}$ 
5,94. Hasil pengujian ketidakrataan benang yang diproduksi menggunakan rotor tipe C341 juga telah memenuhi jaminan kualitas untuk benang $\mathrm{Ne} 6$ pada spindel nomor 7 adalah 12,56 dan untuk spindle nomor 9 adalah 14,22. Nilai Cvm\% telah memenuhi toleransi jaminan kualitas ketidakrataan benang (Cvm\%=1,11-1,25U\%) untuk spesifikasi benang $\mathrm{Ne} 6$.

\section{DAFTAR PUSTAKA}

[1]Basuki Wijaya. $T$ dan Sulistiyadi. "Peningkatan Kualitas Imperfection Indicator (Ipi) Benang P/C Ne1 45 Pada Mesin Ring Spinning Toyoda Model Ry Dengan Setting Variasi Diameter Ring Flange Dan Nomor Traveller," Jurnal Teknika ATW, Vol. 23, No. 1, pp. 95-102, Maret, 2020.

[2] Carissoni, E et. al. 2002. References Books of Textile Technologies: Cotton
And Wool Spinning. ACIMIT Foundation, Italy.

[3] Hananto, A. "Perancangan Dan Pembuatan Sistem Transmisi Regangan (Drafting) Dan Antihan (Twisting) Pada Mesin Ring Spinning Berbasis Mikrokontroller," Jurnal Metal Indonesia, Vol. 40, No. 2, pp. 74-86, Desember, 2018.

[4] Lawrence, C, A. 2010. Advances In Yarn Spinning Technology. Woodhead Publishing Limited, Cambridge.

[5] Senthil Kumar, R. 2015. Process Management in Spinning. CRC Press is an imprint of Taylor \& Francis Group, an Informa business, Broken Sound Parkway NW, Suite 300 Boca Raton.

[6] Thilagavathi, G and Karthik, T. 2015. Process Control and Yarn Quality in Spinning. 1st edition. Woodhead Publishing Limited, New Delhi. 